\title{
Do health insurers possess monopsony power in the hospital services industry?
}

\author{
Laurie J. Bates · Rexford E. Santerre
}

Received: 14 November 2006 / Accepted: 13 June 2007 / Published online: 19 July 2007

(C) Springer Science+Business Media, LLC 2007

\begin{abstract}
This paper uses metropolitan data to test empirically if health insurers possess monopsony or monopoly-busting power on the buyer-side of the hospital services market. According to theory, monopsony power is indicated by a fall in output, whereas, monopoly-busting power is shown by an increase in output when buyer concentration rises. The empirical results provide evidence that greater health insurer buyer concentration is not associated with monopsony power. Instead, some evidence is found to suggest that higher health insurer concentration translates into increased monopoly-busting power. That is, metropolitan hospitals offer increased services when the buyer-side of the hospitals services market is more highly concentrated.
\end{abstract}

Keywords Monopsony $\cdot$ Managed care $\cdot$ Hospital utilization

\section{Introduction}

Since the middle of the 1990s, numerous mergers and consolidations have taken place in the health insurance industry. In fact, the annual number of mergers among managed care companies averaged 43 during the 1994-2005 period and ranged from a low of 27 in 1995 to a high of 66 in 1996 (Kaiser Family Foundation). Notable examples include the Aetna and U.S. Healthcare merger in 1996 and the Anthem and Wellpoint consolidation in 2004. Economic theory suggests that mergers among companies may confer net benefits upon society because of cost efficiencies that result from scale and scope economies. However, economic theory also indicates that horizontal mergers may allow the newly combined company to enjoy the advantage of increased market power. The increased market power may translate

L. J. Bates

Department of Economics, Bryant University, Smithfield 02917, RI, USA

e-mail: lbates@bryant.edu

R. E. Santerre $(\varangle)$

Department of Finance, School of Business, University of Connecticut, Storrs 06269, CT, USA

e-mail: rsanterre@business.uconn.edu 
into higher prices received for products and/or lower prices paid for inputs. Theory suggests that the unbridled exercise of market power in output or input markets can generate net social losses.

In a series of annual reports, the American Medical Association (AMA 2003, 2004, 2005 , 2006) has collected and reported information on the concentration of health insurers in various metropolitan areas of the United States. Based on this data, the AMA finds a health insurance industry that is characterized by a few dominant health insurers and believes that these dominant firms may engage in monopoly and monopsony behavior. Hence, this organization warns that health insurers may raise insurance premiums and thereby reduce the number of insured individuals. In addition, the AMA stresses that health insurers may lower reimbursement rates paid to health care providers and, as a result, cause contrived shortages of medical care.

The AMA is not alone in its concerns. Governor Rendall of Pennsylvania claims that a merger between the state's two largest health insurers, Highmark Inc. and Independence Blue Cross, would harm competition (Snowbeck 2006). The Governor notes that employers in Pennsylvania would be less likely to secure low premiums for health insurance if the merger is allowed. Moreover, nurses at Landmark Medical Center in Rhode Island recently protested outside the office of Blue Cross/Blue Shield of Rhode Island because of the health insurer's failure to pay provider rates that sufficiently compensates for the quality of medical care delivered at the health care facility (Malinowsky 2006).

But are these concerns about the market power of health insurers truly justified on efficiency grounds or do they represent a situation where health care providers are attempting to protect their monopoly rents? Specifically, it is unclear if lower health care provider reimbursement rates by health insurers reflect the exercise of monopsony or monopoly-busting power. If the former, economic theory suggests that the lower price results in efficiency losses. But if the latter, efficiency gains occur from lower prices according to theory. Pauly (1998) and, subsequently, Feldman and Wholey (2001) explain that the only way to determine if health insurers exercise monopsony or monopoly-busting power is by empirically examining the impact of health insurer buying power on the utilization rate of medical services, an input in the production of health insurance. If it can be shown empirically that greater buying power of health insurers is related to lower (increased) utilization of medical services, then the evidence provides support for monopsony (monopoly-busting) behavior.

Feldman and Wholey (2001) provide the only empirical test, to date, for the monopsony versus monopoly-busting theories of health insurer buying power. Specifically, they investigate if health maintenance organizations (HMOs) possess monopsony power in the markets for ambulatory and inpatient hospital services. Using a data set containing all HMOs in the U.S. over the period from 1985 to 1997 and multiple regression analysis, they investigate the importance of an individual HMO, as a single buyer, on the price paid and utilization of inpatient and ambulatory care. Buying power for hospital services is measured by the percentage of inpatient days in the market area purchased by each HMO. Ambulatory buying power is measured by the number of ambulatory visits purchased by each HMO per 1,000 active physicians in the market area. Prices are determined by dividing each type of revenue by the respective quantity measure.

Feldman and Wholey control for a host of supply and demand factors in the regression equation and find that HMO buying power lowers hospital price and increases hospital output. Thus, their evidence suggests that HMOs use their buying clout to bust the monopoly power of hospitals. In addition, they determine that HMO buying power has no statistical impact on the price or output of physician care, perhaps because the physician services market is much more fragmented than the hospital services industry. Overall, Feldman and Wholey conclude 
that HMOs do not exercise monopsony power and that they may have improved efficiency in the hospital services industry through their monopoly-busting power.

While the study by Feldman and Wholey offers valuable insights, it is already dated and fails to consider the role of preferred provider organizations (PPOs). Feldman and Wholey's study covers the years from 1985 to 1997 but many consolidations among health insurers have taken place since that time. The increased consolidations may have conferred greater buying clout such that a single health insurer can more easily exploit its monopsony position. Also, Feldman and Wholey do not consider if PPOs possess monopsony power.

As a result, this study uses more recent data to explore the monopsony power of HMOs and PPOs in the hospital services market. The analysis is conducted at the metropolitan level over the years from 2001 to 2004. Six different measures of hospital output are employed and the buying power of the two types of MCOs is measured by the Herfindahl/Hirschman Index (HHI) of market concentration based on the health insurers' enrollment shares in the various metropolitan areas. An instrumental variables approach is employed to control for the possibility that health insurer concentration is endogenous at the industry level. The empirical results consistently and strongly suggest that HMOs and PPOs do not exercise monopsony power in the typical hospital services market. Indeed, some evidence is found to support the monopoly-busting theory of health insurer concentration.

The next section explains the sample and data and sets up the empirical model. Section three discusses the empirical findings. A summary and some concluding comments are offered in the final section.

\section{Sample, data, and methodology}

The sample used to investigate the impact of MCO buying power on various measures of output in the hospital services industry has its roots in the series of reports issued by the AMA. The AMA began collecting and disseminating information on the concentration of health insurers at the state and metropolitan levels in 2001. Since that time the AMA has issued three additional reports. Each report contains data for the HHI separately for the HMO and PPO segments of the health insurance industry in various metropolitan statistical areas (MSAs) of the U.S. ${ }^{1}$ The number of MSAs covered in the AMA reports has increased over time, growing from 40 in 2001 to 294 in 2004.

Several reasons have been offered for treating HMO and PPO plans as distinctly different health insurance products (US v. Aetna 1999). First, the two plans differ in terms of benefit design, costs, and other factors. For example, HMO plans are more restrictive with features such as gatekeepers and tighter provider networks. In addition, HMOs are known to provide greater preventive care benefits and place limits on treatment options. Second, employers and employees often perceive PPO and HMO plans as different products that meet different needs and appeal to different types of enrollees. In fact, enrollees who drop an HMO plan are disproportionately more likely to choose another HMO plan. Finally, the price elasticity of demand for HMO plans has been found to be relatively low suggesting that very few consumers may switch to PPO plans given an increase in price. As a result, HMO and PPO plans are considered as two different insurance products in the empirical analysis.

The relevant geographical market (RGM) for health insurance is assumed to be the MSA in the AMA reports because Kopit (2004), and others, have argued that the health insurance

\footnotetext{
${ }^{1}$ The HHI is found by summing the squared market shares of all firms in the same market. The HHI ranges between 0 and 10,000 with low values indicating a more competitive market environment. The HHI declines with a greater number of equally sized firms.
} 
marketplace is local in nature since employers and consumers/patients want access to nearby health care provider networks. For example, an employer in Philadelphia would be unlikely to switch to a health insurer with an established network of providers in Boston. In their research on the impact of competitive behavior on the profitability of HMOs, Pauly et al. (2002) assume that the metropolitan area represents the relevant geographical market for health insurance.

In the forthcoming empirical analysis, the MSA is also treated as the RGM for hospital services. While this definition of the RGM is not without its weaknesses (Dravove and White 1994), urban hospital markets are commonly defined in this manner for empirical work (Joskow 1980; Manheim et al. 1994; Spang et al. 2001; Douglas and Ryman 2003; Bates et al. 2006; Santerre and Vernon 2006). But because MSAs like Chicago, Los Angeles, or New York City may be too large for an individual hospital services market, the empirical test is also performed using a subset of MSAs that contain fewer than 2 million people to check the sensitivity of the results.

Bates et al. (2006) argue that treating the metropolitan hospital services industry rather than the individual hospital as the unit of analysis offers a benefit to the econometrician. They note that quality of care and patient case-mix both differ considerably across hospitals within a given geographical area as a result of individual hospitals specializing in the delivery of certain services. For example, Chilingerian and Sherman (2004,p. 485) write; "Hospital A admits more 'fevers of unknown origin' and performs more combined liver kidney transplants, hip replacements, and coronary by-pass grafts and Hospital B has more tooth extractions, vaginal deliveries without complications, and circumcisions, it is an unfair comparison." By focusing on the MSA as the unit of analysis, these supply-side differences across individual hospitals within a given geographical area are averaged out to some degree, thereby allowing a cleaner isolation of the relationship between market factors and hospital services at the MSA level (Keeler and Ying 1996). As the MSA level, the distribution of treatments and quality of care is likely to be more comparable because of closer similarities in the underlying types and severities of illnesses across areas.

Because a panel data set helps to control for unobservable heterogeneity, the sample is defined as those MSAs with at least 2 years of health insurer concentration data over the period from 2001 to 2004 . That restriction results in a total maximum sample size of 344 MSA observations over the 4 year period with a maximum cross-sectional sample of 86 MSAs. While the total number of observations seems relatively small, the 86 MSAs account for over $50 \%$ of the population in the U.S. Thus, the panel data set potentially conveys a considerable amount of useful information on the behavior of health insurers and health care providers.

Health Forum (various years) provides data for six indicators of hospital output. Four direct measures of hospital services are employed: total admissions, total inpatient days, total surgeries, and total outpatient visits. Revenue data necessary for determining price are unavailable so only the impact of health insurer buyer power on output can be empirically observed. Because the monopsony and monopoly busting theories both predict that insurers' buying power should reduce providers' prices, it seems perfectly acceptable to examine the impact of insurer concentration on quantity without examining its impact on price. To check the consistency of the findings, the total number of hospital personnel and labor costs are specified as indirect indicators of hospital services. The expectation is that total labor costs and number of personnel change in the same direction as the direct measures of hospital output given the derived nature of medical inputs such as labor in production.

To isolate the pair-wise correlation between the various measures of health insurer concentration and each indicator of hospital services, it is important to control for as many supply 
and demand factors as possible. However, the lack of consistent time-series/cross-sectional data forced us to be parsimonious in our selection of independent variables. Control variables in the basic model are population, per capita income, and the number of hospitals in the MSA along with a set of time and metropolitan dummy variables. Data for population and income come from the Bureau of Economic Analysis and Health Forum (various years) provides the data for the number of hospitals.

No expectations are made regarding the sign of the estimated coefficients on population and income per capita because they simply control for a host of factors influencing hospital services that relate to scale or physical environment and socioeconomic conditions. However, the sign of the estimated coefficient on the number of community hospitals is expected to be positive for two reasons. First, more hospitals imply an increased supply of hospital services. As long as market demand is not perfectly inelastic, the greater supply will be associated with an increased quantity of hospital services. Second, a single hospital is likely to hold less market power when more hospitals exist in the market area so the quantity of services is expected to be higher.

In an alternative specification, but with fewer observations, the following are specified as additional control variables: the percentage of the population under 15, the percentage of the population over 65 , the percentage of the population with a bachelors degree, the percentage of the population that is white, the percentage of the population that is poor, the unemployment rate, and median value of housing in each MSA during each year. These data are obtained from the American Community Survey website at the U.S. Census Bureau (various years). These variables should help control for the impact of age distribution, education, wealth, and health insurance coverage, among other effects, on the demand for hospital services. Based upon a review of the literature, Scanlon et al. (2006) conclude that the omission of market characteristics such as these affect the conclusions drawn from empirical studies concerning the effects of health insurance competition. As a final test, the alternative model is estimated with a sample of MSAs with fewer than 2 million people because the true RGM for hospital services may be less broadly defined in practice than some of the very large MSAs.

An instrumental variables approach is used to control for the possibility of endogeneity bias. That is, both the level of hospital services, variously measured, and the degree of health insurer concentration may be jointly influenced by some unobservable factors. For example, the expansion decisions of both hospitals and health insurers may be jointly influenced by the health status of people in their market areas. We are unable to control for health status in the empirical analysis. Therefore the concentration of the HMO and PPO submarkets is modeled in the first stage of the two stage multiple regression analysis.

Because employer-sponsored health insurance remains the dominant form of private health insurance in the U.S., the number of firms in the MSA serves as one instrument to capture the size of the employer market. Experimentation shows that this variable fits the first stage model best when specified in quadratic form (in logs). Indicators of firm size distribution have previously been used as instrumental variables in the prediction of the number or market penetration of health insurers (Dranove et al. 1998; Baker and Brown 1999; Town et al. 2007). The size distribution of firms in the MSA is captured in the estimation equation by the average number of employees per firm. Data for the number of firms and employees are obtained from the MSA Business Patterns website at the U.S. Census Bureau (various years).

Finally, the penetration rate of HMOs at the state level in the previous year is specified as an additional instrument. These data come from various issues of the Statistical Abstract of the U.S. The prior year state HMO penetration may indicate the extent to which state regulations such as guarantee issue, community-rated premiums, and state insurance mandates hinder the entry and scale of health insurers. The expectation is that a greater HMO 
penetration at the state level is associated with a lower level of insurer concentration (more health insurers) at the MSA level.

All of these variables are likely to be correlated with health insurer concentration but not the level of hospital output-a necessary property for a good instrumental variable. All variables are expressed in log-form in both the first and second stage regression equations.

Table 1 shows descriptive statistics for the variables used in the various estimation equations. Notice that the average HHI for the HMO and PPO product markets exceeds the threshold for a highly concentrated market of 1,800 as set by the Department of Justice and Federal Trade Commission. Also notice that the HHI varies considerably across MSAs, with the index ranging from just over 1,000 to well over 9,000. Interestingly, the mean HMO-HHI increased from 3,651 in 2001 to 4,323 in 2003 but declined to 4,244 in 2004 (data not shown). Also, the mean PPO-HHI increased from 4,115 in 2001 to 4,599 in 2001 but declined to 4,179 in 2004. Given that the AMA increased the number of MSAs in their sample from 1 year to the next, it is not possible to draw any meaningful implications about the overall trend in industry concentration from their data.

The descriptive statistics in Table 1 also indicate that that a sizeable amount of variation exists in the degree of seller concentration in the various metropolitan hospital services

Table 1 Descriptive statistics

\begin{tabular}{|c|c|c|c|c|c|}
\hline Variable & Mean & $\begin{array}{l}\text { Standard } \\
\text { deviation }\end{array}$ & $\begin{array}{l}\text { Minimum } \\
\text { value }\end{array}$ & $\begin{array}{l}\text { Maximum } \\
\text { value }\end{array}$ & $\begin{array}{l}\text { Number } \\
\text { of observations }\end{array}$ \\
\hline Admissions & 187,613 & 228,664 & 5,070 & $1,341,277$ & 344 \\
\hline Inpatient days & $1,047,509$ & $1,399,997$ & 39,470 & $9,884,548$ & 344 \\
\hline Surgeries & 139,169 & 156,678 & 4,698 & 981,518 & 344 \\
\hline Outpatient visits & $2,694,464$ & $3,487,177$ & 110,068 & $23,545,341$ & 344 \\
\hline Personnel & 21,582 & 27,618 & 855 & 181,500 & 344 \\
\hline Labor expenses & $2,482,720$ & $3,367,972$ & 57,034 & $25,139,710$ & 344 \\
\hline Population & $1,869,673$ & $2,739,524$ & 108,680 & $18,754,585$ & 344 \\
\hline Per capita income & 30,504 & 6,103 & 14,385 & 49,276 & 344 \\
\hline $\begin{array}{l}\text { Number of community } \\
\text { hospitals }\end{array}$ & 16.5 & 17.9 & 1 & 102 & 344 \\
\hline HHI for HMOs & 4043 & 2065 & 1127 & 10000 & 262 \\
\hline HHI for PPOs & 4322 & 1579 & 1370 & 9363 & 265 \\
\hline $\begin{array}{l}\text { Number of Firms } \\
\text { (Employers) }\end{array}$ & 43,644 & 62,873 & 2,797 & 533,528 & 338 \\
\hline Employees per Firm & 16.10 & 2.47 & 10.61 & 23.04 & 338 \\
\hline $\begin{array}{l}\text { HMO state penetration } \\
\text { rate in previous year }\end{array}$ & 30.01 & 13.82 & 6.50 & 53.50 & 344 \\
\hline Percent young & 0.071 & 0.012 & 0.044 & 0.112 & 233 \\
\hline Percent old & 0.122 & 0.036 & 0.072 & 0.274 & 233 \\
\hline Percent white & 0.732 & 0.111 & 0.491 & 0.936 & 233 \\
\hline $\begin{array}{l}\text { Percent with bachelor } \\
\text { degrees }\end{array}$ & 0.108 & 0.032 & 0.0367 & 0.226 & 233 \\
\hline Percent unemployment & 7.467 & 1.831 & 4 & 14 & 233 \\
\hline Percent poverty & 13.536 & 5.527 & 6 & 44 & 233 \\
\hline $\begin{array}{l}\text { Median value of owner- } \\
\text { occupied housing }\end{array}$ & 178,007 & 125,975 & 56,087 & 689,276 & 233 \\
\hline
\end{tabular}


industries. According to the data, about 16 to 17 hospitals operate in the typical MSA in the sample. However, the number of hospitals varies widely from 1 to 102. Although an HHI would be preferred to measure seller concentration for the sake of consistency, the data source provides only the number of community hospitals in each metropolitan area. Fortunately, Wong et al. (2005) show that inferences regarding the broad effect of competition are not sensitive to whether the number of hospitals or HHI is used to measure the intensity of seller competition in the hospital services industry.

\section{Empirical results}

Table 2 provides the regression results for the first stage predicting the HMO and PPO HHIs. According to the results, HMO concentration declines with metropolitan size, as measured by population, whereas PPO concentration increases with metropolitan size. Interestingly, $\mathrm{HMO}$ and PPO concentration both first decline and then increase at some point with respect to the number of firms in the MSA. Also, greater HMO market penetration at the state level in the previous year tends to be associated with lower HHI and PPO concentration, as expected. Finally, the average number of employees per firm evidently influences the number and size distribution of PPOs but not HMOs. Specifically, PPO concentration declines with more employees per firm. More importantly, the set of instruments in each first stage equation has a statistically significant impact on the HHI as determined by a Wald test. In addition, the F-statistics exceeds the threshold value of 10, as set by Staiger and Stock (1997), for detecting weak instruments.

Selected findings for the second stage results are reported in Tables 3 and 4. Recall that monopsony theory predicts a negative coefficient estimate on the HMO-HHI, and PPO-HHI.

Table 2 First stage results for HMO and PPO Concentration

\begin{tabular}{lcc}
\hline & Log of HMO-HHI & Log of PPO-HHI \\
\hline Constant & $39.11^{* *}(3.93)$ & $-2.954(0.16)$ \\
Log of population & $-0.265^{* *}(2.39)$ & $1.679^{* *}(4.45)$ \\
Log of per capita income & $-0.901(1.16)$ & $0.988(0.87)$ \\
Log of number of hospitals & $-0.066(0.90)$ & $-0.047(0.31)$ \\
Log of number of firms & $-3.026^{* *}(3.92)$ & $-2.320^{*}(1.95)$ \\
Log of number of firms squared & $0.130^{* *}(3.76)$ & $0.104^{*}(1.94)$ \\
Log of employees per firm & $0.151(0.46)$ & $-2.826^{* *}(5.25)$ \\
Log of state HMO penetration rate & $-0.336^{* *}(2.92)$ & $-0.546(1.59)$ \\
in previous year & 256 & 259 \\
Number of observations & 0.898 & 0.261 \\
Adjusted $R^{2}$ & $10.96($ prob. $=0.0000)$ & $17.91($ prob. $=0.0000)$ \\
$F$-test for instrumental variables & &
\end{tabular}

Notes: Coefficient estimates with t-statistics reported in parentheses

Cross-section seemingly unrelated standard errors and covariance

All specifications include MSA and time fixed effects

** Indicates statistical significance at the 5\% level

* Indicates statistical significance at the $10 \%$ level 
Table 3 Abbreviated two stage least square results

\begin{tabular}{lcccc}
\hline Measure of Output & $\begin{array}{l}\text { Estimated coefficient } \\
\text { (t-statistic) on HMO-HHI }\end{array}$ & $\begin{array}{l}\text { Estimated coefficient } \\
\text { (t-statistic) on PPO-HHI }\end{array}$ & Adjusted $R^{2}$ & $\begin{array}{l}\text { Number } \\
\text { of observations }\end{array}$ \\
\hline Basic Model $^{\mathrm{a}}$ & & & & \\
Admissions & $0.059(0.82)$ & $-0.021(0.41)$ & 0.998 & 252 \\
Inpatient days & $0.150^{* *}(2.81)$ & $-0.015(0.22)$ & 0.997 & 252 \\
Surgeries & $-0.003(0.02)$ & $0.030(0.38)$ & 0.995 & 252 \\
Outpatient visits & $0.091(0.52)$ & $0.238^{* *}(2.25)$ & 0.987 & 252 \\
Hospital personnel & $0.110(1.17)$ & $-0.093(1.60)$ & 0.990 & 252 \\
Labor expenses & $-0.020(0.18)$ & $-0.056(0.81)$ & 0.997 & 252 \\
Alternative Model & & & & 172 \\
Admissions & $0.081(0.92)$ & $-0.010(0.18)$ & 0.997 & 172 \\
Inpatient days & $0.181^{* *}(2.71)$ & $0.003(0.04)$ & 0.996 & 172 \\
Surgeries & $0.008(0.08)$ & $0.033(0.67)$ & 0.995 & 172 \\
Outpatient visits & $0.220(0.82)$ & $0.199^{* *}(2.20)$ & 0.989 & 172 \\
Hospital personnel & $0.015(0.34)$ & $-0.024(0.46)$ & 0.996 & 172 \\
Labor expenses & $-0.069(0.65)$ & $0.005(0.07)$ & 0.997 & \\
\hline
\end{tabular}

\footnotetext{
a All continuous variables expressed as logs. Control variables include population, per capita income, number of hospitals, and a set of metropolitan dummy variables

b Same as above plus percent young, percent old, percent white, percent with bachelor degrees, percent unemployed, percent poverty, and median value of owner-occupied housing (in logs)

Cross-section seemingly unrelated standard errors and covariance

** Indicates statistical significance at the $5 \%$ level

* Indicates statistical significance at the $10 \%$ level
}

In contrast, positive coefficient estimates on these concentration variables provide empirical support for the monopoly-busting theory. Looking first at the results for the basic equation reported at the top of Table 3, we can see that the estimated coefficient on the HMO-HHI has a negative sign in only two of the six equations. But in those two cases, the coefficient estimates are not statistically significant. In addition, the HMO-HHI possesses a positive and statistically significant coefficient estimate in the inpatient days equations. While the coefficient estimates on the PPO-HHI are negative in 4 of the 6 equations, they are not different from zero at conventional levels of statistical significance. In addition, the PPO-HHI has a positive and statistically significant coefficient estimate in the outpatient visits equation. Taken alone these regression results indicate that health insurers do not possess monopsony power on the buyer side of the hospital services market.

Once additional control variables are added to the basic model, not much change occurs in the magnitude and statistical significance of the estimated coefficients on the HHIs, as shown in the bottom panel of Table 3. Moreover, no statistical evidence is found to support a monopsony view of health insurer concentration. The number of inpatient days is directly related to greater HMO concentration and a direct relationship exists between PPO concentration and the number of outpatient visits.

Table 4 shows the multiple regression findings when the sample is limited to MSAs with fewer than 2 million people. The concern is that the RGM for hospital services market may be too broadly defined in the larger MSAs. These results closely mirror the results for the 
Table 4 Abbreviated two stage least square results for MSAS with fewer than 2 million people

\begin{tabular}{lllll}
\hline Measure of output & $\begin{array}{l}\text { Estimated coefficient } \\
\text { (t-statistic) on HMO-HHI }\end{array}$ & $\begin{array}{l}\text { Estimated coefficient } \\
\text { (t-statistic) on PPO-HHI }\end{array}$ & Adjusted $R^{2}$ & $\begin{array}{l}\text { Number } \\
\text { of observations }\end{array}$
\end{tabular}

$\begin{array}{lcccc}\text { Alternative Model }^{\mathrm{a}} & & & & \\ \text { Admissions } & 0.041(0.59) & -0.052(0.67) & 0.992 & 118 \\ \text { Inpatient days } & 0.186^{* *}(2.92) & -0.042(0.47) & 0.989 & 118 \\ \text { Surgeries } & -0.147(1.13) & -0.114(0.75) & 0.984 & 118 \\ \text { Outpatient visits } & -0.097(0.67) & -0.015(0.19) & 0.985 & 118 \\ \text { Hospital personnel } & 0.056(0.59) & -0.017(0.16) & 0.989 & 118 \\ \text { Labor expenses } & -0.006(0.07) & 0.002(0.02) & 0.992 & 118\end{array}$

a Control variables include population, per capita income, number of community hospitals, percent young, percent old, percent white, percent with bachelor degrees, percent unemployed, percent poverty, median value of owner-occupied housing (all in logs), and MSA and time fixed effects

Cross-section seemingly unrelated standard errors and covariance

** Indicates statistical significance at the $5 \%$ level

* Indicates statistical significance at the $10 \%$ level

larger sample of MSAs. Like before, HMO concentration is directly related to the number of inpatient days. The only difference is that PPO concentration is no longer associated with an increased number of outpatient visits. ${ }^{2}$

All in all, the empirical results strongly suggest that health insurers do not possess monopsony power. In fact, the opposite appears to be true. Greater HMO concentration is shown to be associated with an increased amount of inpatient services and some evidence indicates that higher PPO concentration and outpatient visits are directly related. More specifically, the estimated elasticities suggest that a $10 \%$ increase in HMO concentration is associated with about 1.5-1.9\% more inpatient days. Using sample averages, that percentage difference means 3 more patients per day are treated at the typical hospital on an inpatient basis because of $10 \%$ greater HMO concentration. It also may mean that hospitals are less likely to release patients "quicker and sicker" when health insurers are more influential in their market areas. The results also imply a $10 \%$ increase in PPO concentration may be associated with $2 \%$ more outpatient visits. That percentage translates into nearly 9 more outpatient visits per day at the typical hospital. The implication is that hospitals typically reduce some services and thereby raise price in the absence of health insurer buying power. ${ }^{3}$

\section{Conclusion}

Following the suggestion of Pauly (1998) and lead of Feldman and Wholey (2001), this paper revisits the question of whether health insurers possess monopsony power. The test is conducted by observing the impact of health insurer concentration on the quantity of hospital services. Monopsony (monopoly-busting) theory predicts an inverse (direct) relation between

\footnotetext{
2 The estimated coefficient on the PPO-HHI remains positive and statistically significant in the 0.25 to 0.26 range until a sample cutoff of 4 million people is specified. The statistically insignificant coefficient estimate on the PPO-HHI may reflect that the remaining MSAs are too narrowly defined with respect to the RGM for PPO purchased hospital services after that cutoff point.

${ }^{3}$ As expected, the estimated coefficients are all positive and statistically significant on the number of hospitals.
} 
health insurer concentration and hospital services. This paper extends the literature on this topic by investigating the impact of HMO and PPO concentration on six different measures of services offered by metropolitan hospitals during the period 2001-2004.

Taking all of the empirical results together, it appears that health insurers do not engage in monopsony behavior. The relationships between buyer concentration and the six different measures of hospital services are either direct or statistically insignificant. Consequently, it appears that much of the attention being paid to consolidations among health insurers may largely reflect that health care providers are trying to protect their monopoly rents. In fact, the empirical findings suggest that health insurers, when they possess more buyer clout, can negotiate additional inpatient days and outpatient visits without necessarily raising the number of personnel and labor expenses. This finding agrees with Bates et al. (2006) who find empirically that metropolitan hospitals are more efficient when health insurers dominate the health insurance industry at the state level.

One intriguing aspect of the results concerns the finding that hospital services may be influenced differently depending on whether greater buyer concentration shows up in the HMO or PPO segments of the hospital services industry. It appears that increased buyer concentration from HMOs puts pressure on hospitals to increase inpatient services whereas PPOs may impact the amount of outpatient services. That discrepancy likely reflects that PPO enrollees use outpatient hospital facilities more often than HMO enrollees because the latter typically must obtain prior authorization from their gate-keeper primary care givers.

Because price data are unavailable for the test, we cannot be sure if the ineffectiveness of HMOs and PPOs, with regard to influencing the provision of some types of hospital services like admissions or surgeries, holds because these buyers could not secure price discounts or because they were unable to affect health care provider behavior. ${ }^{4}$ Or it may be the case that inpatient days and outpatient visits are more discretionary at the margin than the other types of services. Future research may want to more thoroughly explore that relationship.

Acknowledgements The authors thank Jon Fanning of the American Medical Association for graciously providing the health insurer concentration data and also Roger Feldman for his suggestions on improving the paper.

\section{References}

AMA (2006). Competition in health insurance: A comprehensive study of U.S. market. Chicago, Illinois; American Medical Association.

AMA (2005). Competition in health insurance: A comprehensive study of U.S. market. Chicago, Illinois: American Medical Association.

AMA (2004). Competition in health insurance: A comprehensive study of U.S. market. Chicago, Illinois: American Medical Association.

AMA (2003). Competition in health insurance: A comprehensive study of U.S. market. Chicago, Illinois: American Medical Association.

Baker, L. C., \& Brown, M. L. (1999). Managed care, consolidation among health care providers, and health care: Evidence from mammography. Rand Journal of Economics, 30(2), 351-374.

Bates, L. J., Mukherjee, K., \& Santerre, R. E. (2006). Market structure and technical efficiency in the hospital services industry. Medical Care Research and Review, 63, 499-524.

Chilingerian, J. A., \& Sherman, H. D. (2004). Health care applications: From hospitals to physicians, from productive efficiency to quality frontiers. In W. W. Cooper, L. M. Seiford, \& J. Zhu (Eds.), Handbook on Data Envelopment Analysis. New York: Kluwer Academic Publishers.

Douglas, T. J., \& Ryman, J. A. (2003). Understanding competitive advantage in the general hospital industry: Evaluating strategic competencies. Strategic Management Journal, 24, 333-347.

4 We thank Doug Wholey for raising this point. 
Dravove, D., \& White, W. (1994). Recent theory and evidence on competition in hospital markets. Journal of Economics and Management Strategy, 3, 170-209.

Dranove, D., Simon, C. J., \& White, W. D. (1998). Determinants of managed care penetration. Journal of Health Economics, 17, 729-745.

Feldman, R., \& Wholey, D. (2001). Do HMOs have monopsony power? International Journal of Health Care Finance and Economics, 1, 7-22.

Health Forum LLC (Various Years). Hospital statistics. Chicago, IL: Health Forum LLC, An American Association Company.

Joskow, P. H. (1980). The effects of competition and regulation on hospital bed supply and the reservation quality of hospitals. Bell Journal of Economics, 11, 421-447.

Kaiser Family Foundation (2006). Trends and Indicators in the Changing Health Care Marketplace. http://www.kff.org/insurance/7031/print-sec5.cfm, (Accessed November 10, 2006).

Keeler, T. E., \& Ying, J. S. (1996). Hospital costs and excess bed capacity: A statistical analysis. The Review of Economics and Statistics, 78, 432-442.

Kopit, W. G. (2004). Is there evidence that recent consolidation in the health insurance industry has adversely affected premiums? Health Affairs, 23(6), 29-31.

Malinowsky, W. Z. (2006). Landmark stages protest at insurer. The Providence Journal (July 28), B1.

Manheim, L., Bazzoli, G., \& Sohn, M. (1994). Local hospital competition in large metropolitan areas. Journal of Economics and Management Strategy, 3, 143-167.

Pauly, M. V. (1998). Managed care, market power, and monopsony. Health Services Research, 33, 1439-1460.

Pauly, M. V., Hillman, A. L., Kim, M. S., \& Brown, D. R. (2002). Competitive behavior in the HMO marketplace. Health Affairs, 21(1), 194-202.

Santerre, R. E., \& Vernon, J. A. (2006). The consumer welfare implications of the hospital ownership mix in the US: An exploratory study. Health Economics, 15, 1187-1199.

Scanlon, D.P., Chernew, M., Swaminathan, S., \& Lee, W. (2006). Competition in health insurance markets: limitations of current measures for policy analysis. Medical Care Research and Review, 63(6 suppl), 37S-55S.

Snowbeck, C. (2006). Rendell worried about blues' merger. Pittsburg Post-Gazette, August 3, A1.

Spang, H. R., Bazzoli, G. R., \& Arnould, R. J. (2001). Hospital mergers and savings for consumers: exploring new evidence. Health Affairs, 20, 150-158.

Staiger, D., \& Stock, J. K. (1997). Instrumental variables regression with weak instruments. Econometrica, 65, 557-586.

Town, R. J., Wholey, D., Feldman, R., \& Burns, L. R. (2007). Revisiting the relationship between managed care and hospital consolidation. Health Services Research, 42, 219-238.

U.S. Census Bureau (various years). MSA Business Patterns. http://censtats.census.gov/cgi-bin/msanaic/msasect.pl (Accessed February 26, 2007).

U. S. Census Bureau. (various years). American Community Survey. http://www.census.gov/acs/www/Products/index.htm, (Accessed February 26, 2007)

United States v. Aetna. (1999). No.:3-99CV1398-H (N.D. Tex.) Revised Competitive Impact Statement filed August 3.

Wong, H. S., Zhan, C., \& Mutter, R. (2005). Do different measures of hospital competition matter in empirical investigations of hospital behaviour. Review of Industrial Organization, 26, 27-60. 